\title{
KINETICS OF CO-PYROLYSIS OF TARFAYA (MOROCCO) OIL SHALE WITH HIGH-DENSITY POLYETHYLENE
}

\author{
A. ABOULKAS $^{(\text {a) }}$, K. EL HARFI ${ }^{*}$ (a), A. EL BOUADILI ${ }^{(\text {b) }}$, \\ M. BENCHANAA ${ }^{(a)}$, A. MOKHLISSE $^{(a)}$, A. OUTZOURIT $^{(c)}$ \\ (a) Laboratoire de Chimie Physique, Departement de chimie, Faculté des Sciences \\ Semlalia, Université Cadi Ayyad, BP 2390, 40001 Marrakech, Maroc \\ (b) Laboratoire de Chimie Organique et Analytique, Departement de chimie, Faculté \\ des Sciences et Techniques de Béni-Mellal, Université Cadi Ayyad, BP 523, \\ 23000 Béni-Mellal, Maroc \\ (c) Laboratoire de Physique des Solides et des Couches Minces, Faculté des \\ Sciences de Marrakech, Semlalia BP S 2390, 40001 Maroc
}

\begin{abstract}
Pyrolysis kinetics of oil shale mixed with high-density polyethylene (HDPE) was investigated using a thermogravimetric analysis (TGA) system at various heating rates of $2,10,20$ and $50 \mathrm{~K} / \mathrm{min}$ in the temperature range of 300$1273 \mathrm{~K}$ in the nitrogen atmosphere. Kissinger-Akahira-Sunose, Friedman, Flynn-Wall-Ozawa and Coats-Redfern methods have been used to determine activation energies of materials degradation. The analysis of the process mechanism by Criado and Coats-Redfern methods showed the following: the mechanism of thermal degradation process of HDPE is describable by the "Contracting cylinder" model (R2 mechanism); and the most probable model for the pyrolysis process of oil shale kerogen is the diffusion model (D4 mechanism), while the mixture degrades following the kinetic model of D4. It has been found that during thermal decomposition of oil shale/HDPE mixture no significant interaction of solid-phase components had taken place under the experimental conditions investigated.
\end{abstract}

\section{Introduction}

Due to population increase, the demand for plastic products has steadily increased over the last years. Since plastics are non-biodegradable, they cannot be easily returned to the natural carbon cycle; hence the life cycle of plastic materials ends at waste disposal facilities. Accumulation of various plastic wastes begins to pose a serious problem.

\footnotetext{
* Corresponding author: e-mail address elharfi@ucam.ac.ma
} 
The plastics constitute a large part of the municipal solid waste (MSW); the current and common MSW management methods used are incineration and landfilling. Both methods have negative environmental impacts. Although, there are incineration methods in which energy is recovered, incinerators generally produce greenhouse gases which are postulated as sources of global warming. Similarly, landfilling poses the threat of methane emissions. Therefore, recycling plays an essential role in developing a sustainable economy and must be considered in any application of plastics. In this respect, the pyrolysis of plastic material has received renewed attention due to he possibility of converting these wastes into useful energetic products or into valuable chemicals [1-3]. Among these plastic wastes, high-density polyethylene (HDPE) represents the largest volume segment of the plastic wastes.

The search for new alternative fuels, together with the necessity of searching new technology to reduce the negative environment impacts of plastic wastes, have led to the idea of studying co-pyrolysis of plastic wastes and oil shale. There is a considerable interest in the efficient conversion of plastic waste mixed with oil shale into clean hydrocarbon fuel or other valuable products.

The plastics consist of hydrocarbons-type macromolecules with a significant intrinsic energy and a very high calorific value [4]. These materials are rich in hydrogen in comparison with coal [5-10] and oil shale [11-15]. Oil shale, on the other hand, is considered to be the substitute for oil as a natural source of energy. However, the extraction of oil from oil shale is relatively expensive and uneconomical. Therefore, research for processes of oil shale utilization as a source of energy is gaining a high level of importance [16-19]. The three oil shale deposits in Morocco (Timahdit, Tanger, and Tarfaya) represent about $15 \%$ of known oil shale resources in the world [20]. Extensive exploration and processing research has been conducted over the past decades [21]. These shale oil resources have been estimated to be 50 billion barrels [20]. Timahdit and Tarfaya oil shale deposits are the biggest and the most explored deposits in Morocco with the potential to yield 17 and 23 billion barrels, respectively.

It has been suggested that the addition of plastics to the oil shale during conversion may result in enhanced conversion of oil shale and production of oil compared with the yields obtained when oil shale alone is treated [12-14]. The co-pyrolysis of oil shale with plastics can, on the one hand, improve the effectiveness of oil shale processing and, on the other hand provide a solution for the waste problem.

For designing pyrolysis procedure, the behaviour of oil shale mixed with HDPE during thermal decomposition with regard to the decomposition products and decomposition kinetics must be known. The characteristics of pyrolytic degradation of oil shale mixed with HDPE have been studied by thermogravimetry (TGA). 
The present work was carried out in order to understand and predict the yield and quality of the product generated by co-pyrolysis of oil shale and HDPE. To achieve this goal, TG analysis of HDPE, oil shale and their mixture was performed first. The effect of heating rate was studied. A kinetic model is proposed which allows a good correlation of the results obtained.

\section{Theoretical approach}

The kinetics of thermal decomposition reactions of carbonaceous materials is complex as the process involves a large number of reactions in parallel and in series. Although TGA provides general information on the overall reaction kinetics, rather than individual reactions, it could be used as a tool for providing comparison of kinetic data of various reaction parameters such as temperature and heating rate. Other advantages include only a single sample, and few data are required for obtaining kinetics over an entire temperature range.

The pyrolysis process may be represented by the following reaction scheme:

$$
A_{\text {(solid) }} \rightarrow B_{(\text {solid })}+C_{(\text {volatile })}
$$

The rate of conversion, $d x / d t$ for TG experiment at constant rate of temperature change, $\beta=d T / d t$, may be expressed by

$$
\frac{d x}{d t}=\beta \frac{d x}{d T}=K(T) f(x),
$$

where $x$ is the degree of advance defined by

$$
x=\frac{w_{0}-w}{w-w_{f}},
$$

where $w$ is the weight of the sample at a given time $t, w_{0}$ and $w_{f}$ refer to values at the beginning and the end of the weight loss event of interest. $f(x)$ and $K(T)$ are functions of conversion and temperature, respectively.

$K(T)$, the temperature dependence of the rate of weight loss, is often modeled successfully by the Arrhenius equation

$$
K(T)=A \exp \left(-\frac{E}{R T}\right),
$$

where $E$ is activation energy, $A$ pre-exponential factor, and $R$ gas constant.

By combining Eqs. (1) and (3), reaction rate can be written in the form

$$
\beta \frac{d x}{d T}=A \exp \left(-\frac{E}{R T}\right) f(x) .
$$


Kissinger-Akahira-Sunose method (KAS method) [22, 23]

The standard Eq. (4) can be shown as follows:

$$
\frac{d x}{f(x)}=\frac{A}{\beta} \exp \left(-\frac{E}{R T}\right) d T
$$

which is integrated with the initial condition of $x=0$ at $T=T_{0}$ to obtain the following expression:

$$
g(x)=\int_{0}^{x} \frac{d x}{f(x)}=\frac{A}{\beta} \int_{T_{0}}^{T} \exp \left(-\frac{E}{R T}\right) d T \equiv \frac{A E}{\beta R} p\left(\frac{E}{R T}\right)
$$

Essentially the technique assumes that $A, f(x)$ and $E$ are independent of $T$ while $A$ and $E$ are independent of $x$, then Eq. (6) may be integrated to give the following equation in logarithmic form:

$$
\ln g(x)=\ln \left(\frac{A E}{R}\right)-\ln \beta+\ln p\left(\frac{E}{R T}\right)
$$

The KAS method is based on the Coats-Redfern approximation [24] according to which

$$
p\left(\frac{E}{R T}\right) \cong \frac{\exp \left(-\frac{E}{R T}\right)}{\left(\frac{E}{R T}\right)^{2}}
$$

From relationships (6) and (8) it follows that:

$$
\ln \frac{\beta}{T^{2}}=\ln \frac{A R}{E g(x)}-\frac{E}{R T}
$$

Thus, the plot $\ln \left(\beta / T^{2}\right)$ vs. $1 / T$ for a constant value of $x$ should be a straight line whose slope can be used to evaluate activation energy.

\section{Friedman method [25]}

This method is a differential isoconversional method, and is directly based on Eq. (4) whose logarithm is

$$
\ln \left(\frac{d x}{d t}\right)=\ln \left(\beta \frac{d x}{d T}\right)=\ln [A f(x)]-\frac{E}{R T} .
$$

From this equation, it is easy to obtain values for $E$ over a wide range of conversions by plotting $\ln \left(\beta \frac{d x}{d T}\right)$ against $\frac{1}{T}$ for a constant $x$ value. 


\section{Flynn-Wall-Ozawa [26, 27]}

This method is derived from integral isoconversional method. Using Doyle's approximation [28] for the integral which allows

$$
\left(\ln p\left(\frac{E}{R T}\right) \cong-5.331-1.052 \frac{E}{R T}\right),
$$

Eq. (7) now can be simplified as

$$
\ln \beta=\ln \frac{A E}{R g(x)}-5.331-1.052 \frac{E}{R T} .
$$

Thus, for $x=$ const., the plot $\ln \beta$ vs. $1 / T$, obtained from thermograms recorded at several heating rates, should be a straight line whose slope can be used to evaluate activation energy.

\section{Coats-Redfern method [24]}

Coats-Redfern method is also an integral method, and it involves the mechanism of thermal degradation. Using an asymptotic approximation for resolution of Eq. $6(2 R T / E\langle\langle 1)$, the following equation can be obtained:

$$
\ln \frac{g(x)}{T^{2}}=\ln \frac{A R}{\beta E}-\frac{E}{R T} \text {. }
$$

\section{Criado method [29]}

If the value of the activation energy is known, the kinetic model of the process can be determined by this method. Combining Eq. 4 with Eq. 12, the following equation is obtained:

$$
\frac{Z(x)}{Z(0.5)}=\frac{f(x) g(x)}{f(0.5) g(0.5)}=\left(\frac{T_{x}}{T_{0.5}}\right)^{2} \frac{(d x / d t)_{x}}{(d x / d t)_{0.5}},
$$

where 0.5 refers to the conversion in $x=0.5$.

The left side of Eq. (13) $\frac{f(x) g(x)}{f(0.5) g(0.5)}$ is a reduced theoretical curve, which is characteristic of each reaction mechanism, whereas the right side of the equation associated with the reduced rate can be obtained from experimental data. A comparison of both sides of Eq. (13) tells us which kinetic model describes an experimental reactive process. Table 1 gives algebraic expressions of $\mathrm{f}(x)$ and $\mathrm{g}(x)$ for the kinetic models used. 
Table 1. Algebraic expressions of functions of the most common reaction mechanisms operating in solid-state reactions

\begin{tabular}{|l|c|c|}
\hline \multicolumn{1}{|c|}{ Mechanism } & $f(x)$ & $g(x)$ \\
\hline Power law (P2) & $2 x^{1 / 2}$ & $x^{1 / 2}$ \\
Power law (P3) & $3 x^{2 / 3}$ & $x^{1 / 3}$ \\
Power law (P4) & $4 x^{3 / 4}$ & $x^{1 / 4}$ \\
Avarami-Erofe'ev (A2) & $2(1-x)[-\ln (1-x)]^{1 / 2}$ & {$[-\ln (1-x)]^{1 / 2}$} \\
Avarami-Erofe'ev (A3) & $3(1-x)[-\ln (1-x)]^{2 / 3}$ & {$[-\ln (1-x)]^{1 / 3}$} \\
Avarami-Erofe'ev (A4) & $4(1-x)[-\ln (1-x)]^{3 / 4}$ & {$[-\ln (1-x)]^{1 / 4}$} \\
Contracting area (R2) & $2(1-x)^{1 / 2}$ & {$\left[1-(1-x)^{1 / 2}\right]$} \\
Contracting volume (R3) & $3(1-x)^{2 / 3}$ & {$\left[1-(1-x)^{1 / 3}\right]$} \\
Diffusion models & $1 / 2 x$ & $x^{2}$ \\
One-dimensional diffusion (D1) & {$[-\ln (1-x)]^{-1}$} & {$[(1-x) \ln (1-x)]+x$} \\
Two-dimensional diffusion (D2) & $\left(1-(1-x)^{1 / 3}\right]^{2}$ \\
Three-dimensional diffusion, Jander & $3(1-x)^{2 / 3} /\left[2\left(1-(1-x)^{1 / 3}\right)\right]$ & {$[1-(1-x)$} \\
(D3) & $3 / 2\left((1-x)^{-1 / 3}-1\right)$ & $1-(2 x / 3)-(1-x)^{2 / 3}$ \\
Ginstling-Brounshtein (D4) & $(1-x)$ & $-\ln (1-x)$ \\
Reaction-order models & $(1-x)^{2}$ & $(1-x)^{-1}-1$ \\
First-order reaction (F1) & $(1-x)^{3}$ & {$\left[(1-x)^{-2}-1\right] / 2$} \\
Second-order reaction (F2) & & \\
Third-order reaction (F3) & &
\end{tabular}

\section{Experimental}

\section{Materials}

The oil shale used in this work was from the Tarfaya deposit located in the south of Morocco. This deposit consists of several layers that are in turn subdivided in sub-layers, each containig a different amount of organic matter. The samples were obtained from the R3 sub-layer, characterized by its high content of organic matter [20]. The results of the analysis of these samples are given in Table 2 .

A sample from Tarfaya oil shale was obtained from the Moroccan "Office National de Recherche et d'Exploitation Pétrolière (ONAREP)". The vitrinite reflectance $R_{0}=0.32 \pm 0.04 \%$ indicated the immaturity of the sediment. No inertinite was found.

The kerogen concentrate was prepared by a method described as follows: finely ground samples were Soxhlet-extracted for $24 \mathrm{~h}$ with chloroform. The solution was then filtered and the solvent eliminated in a rotary apparatus at reduced pressure (to eliminate bitumen). Pre-extracted samples were treated with diluted $\mathrm{HCl}, \mathrm{HF}$ and $\mathrm{HCl}$ successively to eliminate carbonates and silicates. Pyrite was removed by the method of density difference. The 
$\mathrm{H} / \mathrm{C}$ and $\mathrm{O} / \mathrm{C}$ atomic ratios (1.62 and 0.14 , respectively) correspond to a lowmaturity type II kerogen [30, 31].

\section{Table 2. Some average physicochemical characteristics of Tarfaya oil shales}

\begin{tabular}{|l|r|}
\hline Proximate analysis (wt.\%) & \\
Volatile matter & 40.09 \\
Ash & 52.83 \\
Moisture (as received) & 5.15 \\
Elemental analysis (wt.\%) & 17.60 \\
C & 1.78 \\
H & 0.70 \\
N & 0.37 \\
S & \\
Composition (wt.\%) & 70.00 \\
Carbonate mineral (by HCl leaching) & 10.00 \\
Silicate mineral (by HF- $\mathrm{HCl}$ leaching) & 0.80 \\
Bitumen (by Soxhlet extraction with $\mathrm{CHCl}_{3}$ & 1.00 \\
Pyrite (by density separation $\mathrm{CHCl}_{3}$ ) & 17.00 \\
Kerogen & \\
\hline
\end{tabular}

The samples of high-density polyethylene (HDPE) were provided by Plador (Marrakech, Morocco); the results of characterization of these materials are given in Table 3. The oil shale samples were ground and sieved to give particle size of $0.1 \mathrm{~mm}$. The (1:1) oil shale/HDPE mixture was blended by tumbling for $30 \mathrm{~min}$ in order to achieve homogeneity. In all experiments, samples of around $20 \mathrm{mg}$, particle size ranging approximately from 0.1 and $0.2 \mathrm{~mm}$, were placed in the platinum crucible of a thermobalance.

\section{Table 3. Some characteristics of HDPE}

\begin{tabular}{|l|r|}
\hline Proximate analysis (wt.\%) & \\
Volatile matter & 98.36 \\
Ash & 1.60 \\
Elemental analysis (wt. \%) & \\
C & 84.95 \\
H & 14.30 \\
N & 0.55 \\
S & - \\
\hline
\end{tabular}

\section{Experimental Techniques}

Oil shale, HDPE and their mixture samples were subjected to thermogravimetric analysis (TGA) in the inert atmosphere of nitrogen. Rheometrix 
Scientific STA 1500 TGA analyzer was used to measure and record the change in sample mass with temperature over the course of the pyrolysis reaction. Thermogravimetric curves were obtained at four different heating rates $(2,10,20$ and $50 \mathrm{~K} / \mathrm{min})$ between $300 \mathrm{~K}$ and $1275 \mathrm{~K}$; the precision of reported temperatures was estimated to be $\pm 2{ }^{\circ} \mathrm{C}$. Nitrogen gas was used as an inert purge gas to displace air in the pyrolysis zone, thus avoiding unwanted oxidation of the sample. Nitrogen was fed to the system from a point below the sample at the flow rate of around $60 \mathrm{ml} / \mathrm{min}$ and a purge time of $60 \mathrm{~min}$ (to be sure the air was eliminated from the system and the atmosphere was inert). The balance can hold a maximum of $45 \mathrm{mg}$; therefore, all sample amounts used in this study averaged approximately $20 \mathrm{mg}$.

The reproducibility of the experiments is acceptable and the experimental data presented in this paper corresponding to the different operating conditions are the mean values of runs carried out two or three times.

\section{Results and Discussion}

\section{Thermogravimetric Analysis}

Thermal decomposition of HDPE

TG and DTG curves of thermal decomposition of HDPE at four heating rates are presented in Fig. 1. One can see that the shape of the weight loss curves does not change with variations in heating rate, but weight loss temperatures show an increase at higher heating rates. The weight loss shows that degradation occurs almost totally in one step as there is only one peak in DTG.

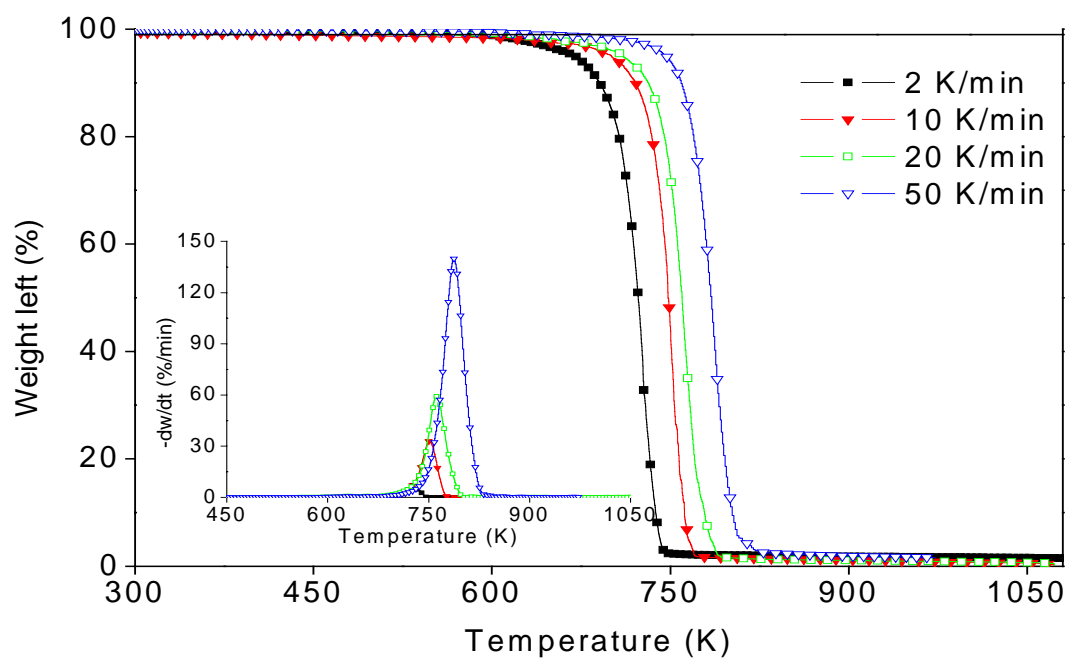

Fig. 1. TG curves of HDPE at different heating rates. Inset: corresponding DTG curves. 
TG curves show that thermal degradation of HDPE starts at $654 \mathrm{~K}$ and is almost complete at approximately $854 \mathrm{~K}$. At higher heating rate the maximum degradation rate shifted from $728 \mathrm{~K}$ at $2 \mathrm{~K} / \mathrm{min}$ to $779 \mathrm{~K}$ at $50 \mathrm{~K} / \mathrm{min}$. The maximum degradation rate also increased from $7.37 \% / \mathrm{min}$ at $2 \mathrm{~K} / \mathrm{min}$ to $140.25 \% / \mathrm{min}$ at $50 \mathrm{~K} / \mathrm{min}$. DTG and TG curves were shifted to higher temperature due to the heat transfer enlarging with increasing heating rate. TG/DTG/DTA curves at the heating rate of $10 \mathrm{~K} / \mathrm{min}$ are shown in Fig. 2. Two peaks corresponding to endothermic reactions are observed in the DTA curve. The first peak corresponds to melting of HDPE, which begins at $350 \mathrm{~K}$ and continues up to $445 \mathrm{~K}$, without an accompanying weight loss. The second peak corresponds to the decomposition reaction.

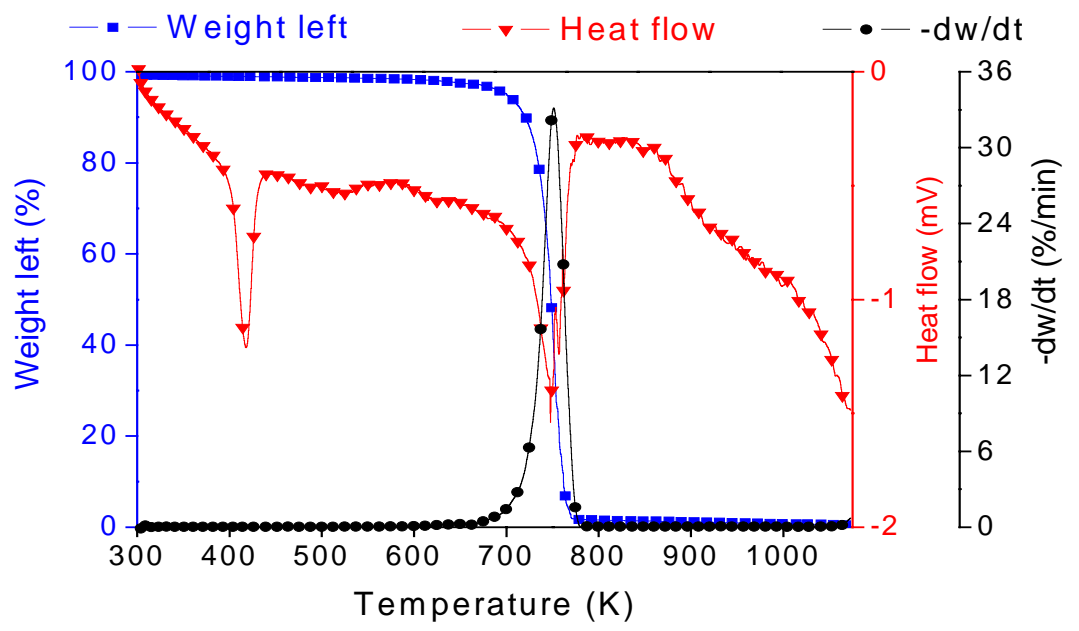

Fig. 2. TG/DTG/DSC curves of HDPE at a heating rate of $10 \mathrm{~K} / \mathrm{min}$

\section{Thermal decomposition of oil shale}

TG and DTG curves at different heating rate for thermal decomposition of oil shale are shown in Fig. 3. The approximate similarity between the curves indicates that weight loss is independent of heating rate. TG/DTG/DTA curves of oil shale at a heating rate of $10 \mathrm{~K} / \mathrm{min}$ in nitrogen are shown in Fig. 4. The DTA peaks closely correspond to the changes observed on the TG curves. The curves showed that thermal decomposition occurs in three steps. The first step from 300 to $375 \mathrm{~K}$, characterized by an endothermic peak at $325 \mathrm{~K}$, corresponds to drying of oil shale. The second step (at about $592-776 \mathrm{~K}$ ) demonstrates a weight loss of $9 \%$ due to decomposition of the organic matter. The heat requirement for this reaction is low, as shown by the small peak in DTA curve in Fig. 4. The last weight loss, which begins at $810 \mathrm{~K}$, shows a strong endothermic reaction manifested in a high peak in DTA curve at $1012 \mathrm{~K}$. This stage shows a mass loss of $36 \%$ due to 


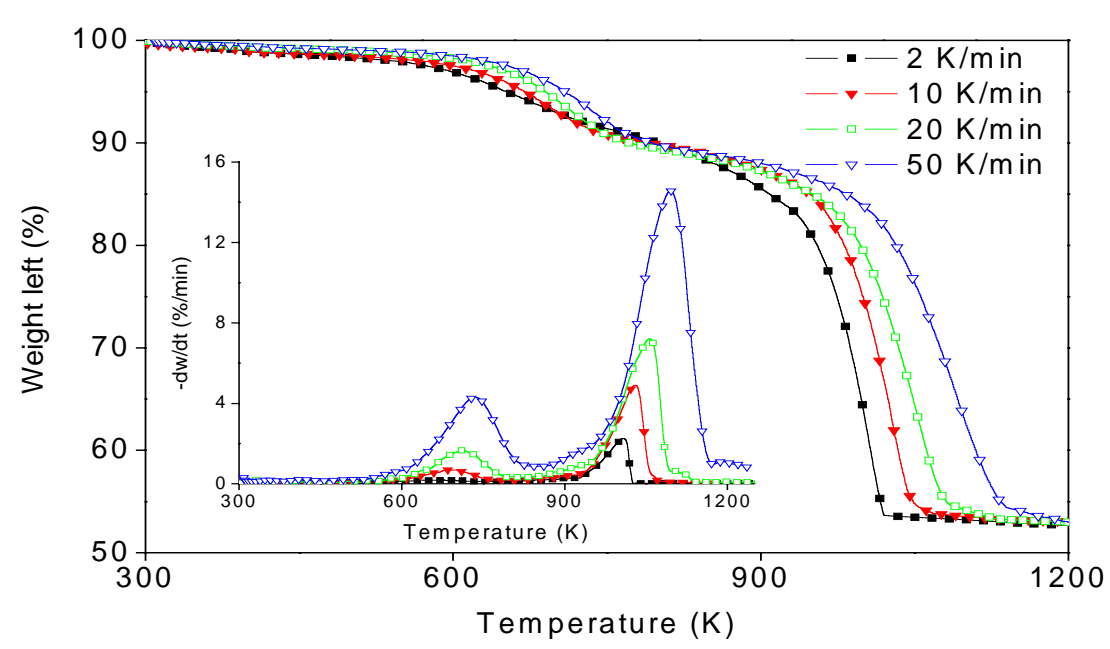

Fig. 3. TG curves of oil shale at different heating rates. Inset: corresponding DTG curves

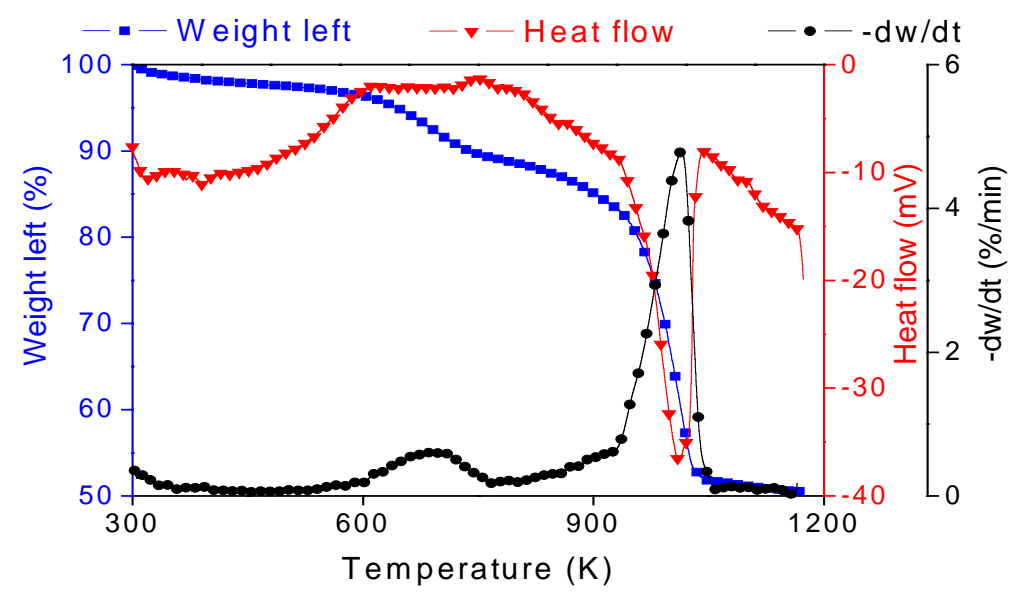

Fig. 4. TG/DTG/DSC curves of oil shale at a heating rate of $10 \mathrm{~K} / \mathrm{min}$

decomposition of the mineral matter in oil shale (mainly decomposition of carbonates and silicates).

There was a lateral shift to higher temperature for temperatures as the heating rate was increased as illustrated in Fig. 3. The rate of weight loss also reflects the lateral shift with an increase in the rate as the heating rate was increased from $2 \mathrm{~K} / \mathrm{min}$ to $50 \mathrm{~K} / \mathrm{min}$. The residual weights seemed to reach some constant values after $1200 \mathrm{~K}$. The values of residual weight were calculated to be about $52.9 \mathrm{wt} \%$. The lateral shift to higher temperatures for the maximum region of weight loss has also been observed by other workers using TGA to investigate pyrolysis of oil shales. For example, Gersten et al. 
[15] showed a lateral increase in the maximum rate of weight loss of about $38^{\circ} \mathrm{C}$ when the heating rate was increased from 5 to $50 \mathrm{~K} / \mathrm{min}$ for Israel oil shale. Thakur and Nuttall [32] and Jaber and Probert [33] also showed a lateral shift in the maximum rate of weight loss for the TGA of oil-shale samples. Rajeshwar [34] suggested that the shift to higher temperatures of decomposition presented differences in the rate of heat-transfer to the sample as the heating rate was varied.

\section{Thermal decomposition of the mixture}

Figure 5 shows the TG/DTG curves obtained at four heating rates of 2, 10, 20 and $50 \mathrm{~K} / \mathrm{min}$. One can see that decomposition of organic matter (kerogen) of oil shale overlaps with decomposition of HDPE. The main phenomena characterizing the degradation of separate components appear also in the mixture. It should be added that the yield of residue from the mixture is lower than that of oil shale alone.

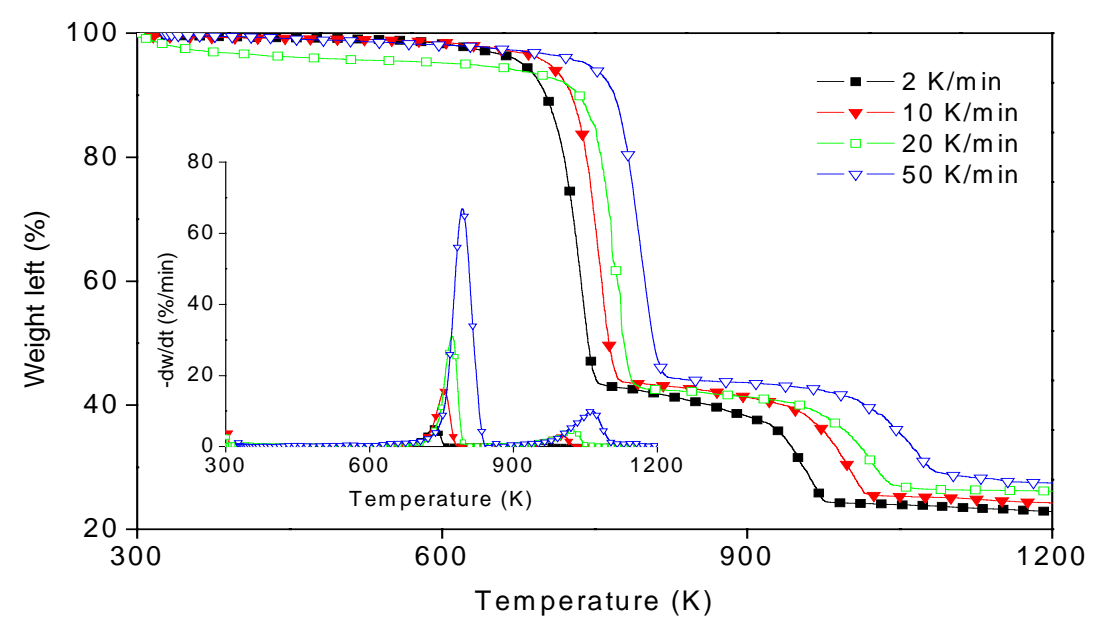

Fig. 5. TG curves of mixture at different heating rates. Inset: corresponding DTG curves

The TG/DTG/DTA curves at a heating rate of $10 \mathrm{~K} / \mathrm{min}$ are depicted in Fig. 6 which shows that decomposition proceeds through three steps (see TG curves). The first step, recorded in the temperature range $300-380 \mathrm{~K}$, is attributed to the release of the adsorbed water from the sample. The DTA peak of this stage overlaps with that of melting of HDPE. The second step occurs between 684 and $776 \mathrm{~K}$ and exhibits a total weight loss of $58.3 \mathrm{wt} . \%$, which corresponds to overlapping decomposition of the organic matter of oil shale and HDPE. The third step between 900 and $1030 \mathrm{~K}$ with $15.4 \mathrm{wt} . \%$ weight loss is attributed to decomposition of the mineral matter of oil shale in the mixture (carbonates and silicates). 


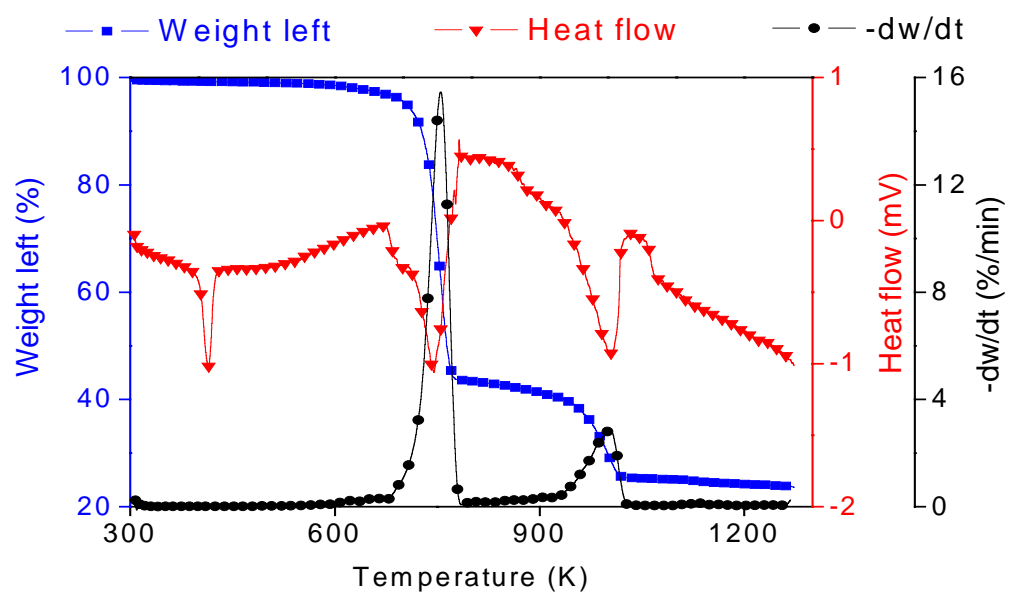

Fig. 6. TG/DTG/DSC curves of mixture at a heating rate of $10 \mathrm{~K} / \mathrm{min}$

In the case of both oil shale and HDPE, characteristic temperatures of the process depend on heating rate. Higher heating rates shifted the residual weight curve rightward to the higher temperature range. The percentage by weight of residues were calculated to be about $22.8 \%, 24.2 \%, 26.1 \%$ and $27.3 \%$ corresponding to heating rates of $2,10,20$ and $50 \mathrm{~K} / \mathrm{min}$, respectively. The amount of residual fraction increases with increasing heating rate.

To investigate whether oil shale interacts with HDPE, let us compare the experimental and calculated curves for the mixture illustrated in Figs. 7 and 8, respectively. Comparing TG and DTG curves, it is concluded that no significant interactions occur in the solid phase during co-pyrolysis. The shape of curves and the positions of peaks remain basically unaltered. However, possible synergistic affects in the gaseous or gas-solid phase may occur.

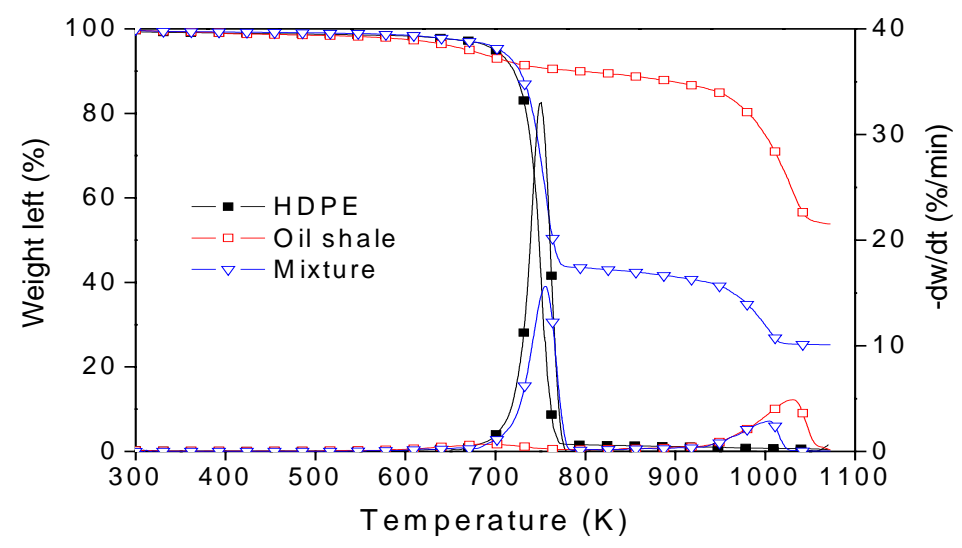

Fig. 7. Experimental TG and DTG-curves of oil shale/HDPE mixture obtained at $10 \mathrm{~K} / \mathrm{min}$ 


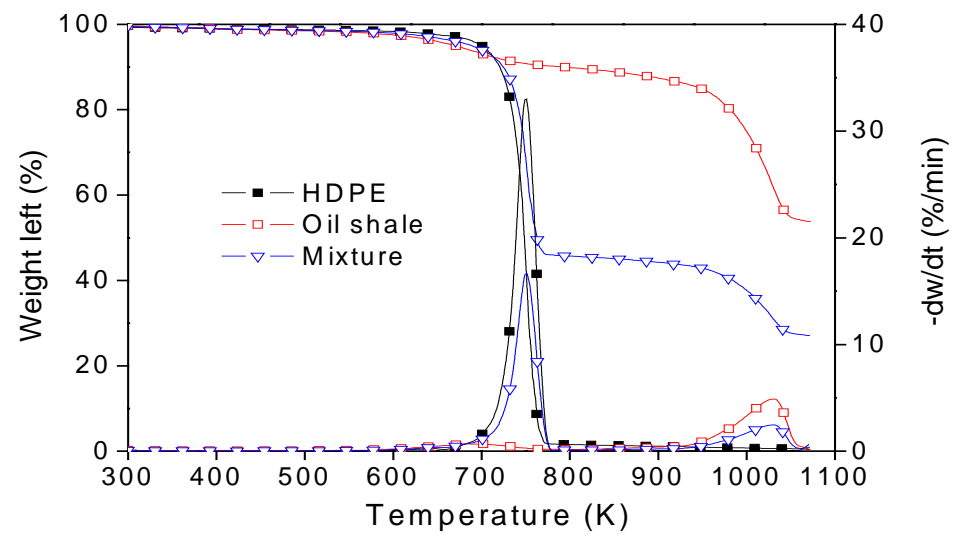

Fig. 8. TG and DTG-curves obtained by calculation of oil shale/HDPE mixture at $10 \mathrm{~K} / \mathrm{min}$

\section{Kinetics of thermal decomposition}

A thermogravimetric study consists of performing a kinetic analysis which includes recording of weight loss curves at different heating rates in order to deduce the dependence of kinetic parameters on conversion level. KAS method has been firstly employed to analyse TG data of materials. Eq. (9) has been used to calculate the values of activation energy from the plot of $\ln \left(\left(\beta / T^{2}\right)\right)$ versus $1 / T$ fitting to a straight line. The results are given in Table 4. The values of activation energy of thermal degradation of HDPE, oil shale and their mixture are 238, 80 and $192 \mathrm{~kJ} / \mathrm{mol}$, respectively.

Table 4. Activation energies of HDPE, oil shale and mixture obtained by Kissinger- Akahira-Sunose method

\begin{tabular}{|c|c|c|c|c|c|}
\hline \multicolumn{2}{|c|}{ HDPE } & \multicolumn{2}{c|}{ Oil shale } & \multicolumn{2}{c|}{ Mixture } \\
\hline$x$ & $\begin{array}{l}\text { Activation } \\
\text { energy (kJ/mol) }\end{array}$ & $x$ & $\begin{array}{l}\text { Activation } \\
\text { energy }(\mathrm{kJ} / \mathrm{mol})\end{array}$ & $x$ & $\begin{array}{l}\text { Activation } \\
\text { energy }(\mathrm{kJ} / \mathrm{mol})\end{array}$ \\
\hline 0.1 & 207 & 0.04 & 91 & 0.15 & 172 \\
0.2 & 235 & 0.06 & 66 & 0.20 & 188 \\
0.3 & 242 & 0.08 & 64 & 0.25 & 189 \\
0.4 & 247 & 0.10 & 70 & 0.30 & 195 \\
0.5 & 249 & 0.12 & 81 & 0.35 & 194 \\
0.6 & 250 & 0.14 & 85 & 0.40 & 196 \\
0.7 & 248 & 0.16 & 83 & 0.45 & 193 \\
0.8 & 249 & 0.18 & 102 & 0.50 & 195 \\
0.9 & 245 & & & 0.55 & 195 \\
& & & & 0.60 & 195 \\
& & & & 0.65 & 197 \\
Mean & $238 \pm 11$ & Mean & $80 \pm 9$ & Mean & $192 \pm 7$ \\
\hline
\end{tabular}


Another derivative method used in this paper is Friedman's method, which is probably the most general of the derivative techniques. This method is based on the intercomparison of the rates of weight loss $d x / d t$ with different linear heating rates $\beta$ for a given fractional weight loss. Eq. (10) has been applied to determine the values of activation energies from plots of $\ln \left(\left(\beta / T^{2}\right)\right)$ versus $1 / T$ over a wide range of conversion level. The calculated results have been summarized in Table 5. The mean values of $E$ 247,85 and $207 \mathrm{~kJ} / \mathrm{mol}$ for HDPE, oil shale and mixture, respectively, are somewhat higher than the values obtained by Kissinger-Akahira-Sunose method.

Table 5. Activation energies of HDPE, oil shale and mixture obtained by Friedman's method

\begin{tabular}{|c|c|c|c|c|c|}
\hline \multicolumn{2}{|c|}{ HDPE } & \multicolumn{2}{c|}{ Oil Shale } & \multicolumn{2}{c|}{ Mixture } \\
\hline$x$ & $\begin{array}{c}\text { Activation } \\
\text { energy (kJ/mol) }\end{array}$ & $x$ & $\begin{array}{c}\text { Activation } \\
\text { energy }(\mathrm{kJ} / \mathrm{mol})\end{array}$ & $x$ & $\begin{array}{c}\text { Activation } \\
\text { energy }(\mathrm{kJ} / \mathrm{mol})\end{array}$ \\
\hline 0.1 & 247 & 0.04 & 72 & 0.15 & 205 \\
0.2 & 257 & 0.06 & 81 & 0.20 & 213 \\
0.3 & 256 & 0.08 & 79 & 0.25 & 212 \\
0.4 & 255 & 0.10 & 83 & 0.30 & 213 \\
0.5 & 252 & 0.12 & 85 & 0.35 & 211 \\
0.6 & 232 & 0.14 & 90 & 0.40 & 209 \\
0.7 & 235 & 0.18 & 87 & 0.45 & 207 \\
0.8 & 248 & & 100 & 0.50 & 204 \\
0.9 & 237 & & & 0.55 & 200 \\
& & & & 0.60 & 198 \\
Mean & $247 \pm 6$ & Mean & $85 \pm 7$ & 0.65 & 205 \\
\end{tabular}

Flynn-Wall-Ozawa method is an integral method also being independent of the degradation mechanism. Eq. (11) has been used and the apparent activation energy of HDPE can therefore be obtained from a plot of $\ln \beta$ against $1 / T$ for a fixed conversion level since the slope of such a line is given by $1.052(E / R T)$. The activation energies calculated form the slopes are tabulated in Table 6 . The mean values of $E$ of HDPE, oil shale and mixture are 243, 87 and $199 \mathrm{~kJ} / \mathrm{mol}$, respectively.

The calculated apparent activation energies for HDPE reported in the literature vary over a wide range. R. Aguado et al. [35] reported activation energy of HDPE degradation $260 \pm 23 \mathrm{~kJ} / \mathrm{mol}$, L. Sorum et al. [36] found for HDPE degradation activation energy of $445 \mathrm{~kJ} / \mathrm{mol}$. C. H. Wu et al. [37] used thermogravimetry to study pyrolysis of plastic mixtures of MSW, the apparent activation energy of HDPE degradation was found to be $233 \mathrm{~kJ} / \mathrm{mol}$. 
Table 6. Activation energies of HDPE, oil shale and mixture obtained by FlynnWall-Ozawa method

\begin{tabular}{|c|c|c|c|c|c|}
\hline \multicolumn{2}{|c|}{ HDPE } & \multicolumn{2}{c|}{ Oil Shale } & \multicolumn{2}{c|}{ Mixture } \\
\hline$x$ & $\begin{array}{l}\text { Activation } \\
\text { energy }(\mathrm{kJ} / \mathrm{mol})\end{array}$ & $x$ & $\begin{array}{l}\text { Activation } \\
\text { energy }(\mathrm{kJ} / \mathrm{mol})\end{array}$ & $x$ & $\begin{array}{l}\text { Activation } \\
\text { energy }(\mathrm{kJ} / \mathrm{mol})\end{array}$ \\
\hline 0.1 & 208 & 0.04 & 104 & 0.15 & 187 \\
0.2 & 236 & 0.06 & 72 & 0.20 & 193 \\
0.3 & 244 & 0.08 & 69 & 0.25 & 194 \\
0.4 & 248 & 0.10 & 77 & 0.30 & 201 \\
0.5 & 250 & 0.12 & 87 & 0.35 & 199 \\
0.6 & 252 & 0.14 & 92 & 0.40 & 201 \\
0.7 & 249 & 0.16 & 89 & 0.45 & 199 \\
0.8 & 250 & 0.18 & 109 & 0.50 & 201 \\
0.9 & 247 & & & 0.55 & 201 \\
& & & & 0.60 & 207 \\
Mean & $243 \pm 10$ & Mean & $87 \pm 10$ & 0.65 & 202 \\
\hline
\end{tabular}

Comparison with literature data shows that kinetic parameters characterizing each individual oil shale are unique. Torrente and Galan [38] determined activation energy of $167 \mathrm{~kJ} / \mathrm{mol}$ for non-isothermal TGA of Puertollano (Spain) oil shale. Sonibare with coworkers [39] performed non-isothermal TGA on Lokpanta oil shales (Nigeria) and found the activation energy to vary from 73.2 to $75 \mathrm{~kJ} / \mathrm{mol}$. Dogan and Uysal [40], however, reported the results for Turkish oil shale to be of approximately $25 \mathrm{~kJ} / \mathrm{mol}$ at low-temperature decomposition, and up to $43 \mathrm{~kJ} / \mathrm{mol}$ at the main stage of decomposition.

The difference between the results determined by our study and literary data is probably due to the influence of process parameters, such as heating rate and particle size. In addition, oil shale, especially its kerogen, is characterized by a complex heterogeneous nature; hence, it would be difficult to obtain the same experimental results even for nominally the same sample. Therefore, the same experimental technique, including sample preparation procedure, analysis method adopted, and the kinetic model for the analysis, should be employed in order to enable a reasonable comparison to be achieved.

In order to establish the kinetic model of thermal degradation, the Criado and Coats-Redfern methods were chosen as they involve degradation mechanisms. The used models and the expressions of associated functions $\mathrm{g}(\mathrm{x})$ and $\mathrm{f}(\mathrm{x})$ are shown in Table 1. The master curve plots $Z(x) / Z(0.5)$ versus $x$ for different mechanisms according to the Criado method for HDPE degradation are illustrated in Fig. 9. Firstly, it shows the experimental data with theoretical curves corresponding to R2, R3 and F1 models for HDPE. The comparison of the experimental master plots with theoretical ones revealed that the kinetics of the degradation process of oil shale kerogen is most probably describable by the Avrami-Erofeyev (An) and diffusion (Dn) models, since the experimental master plots lay between the theoretical master 


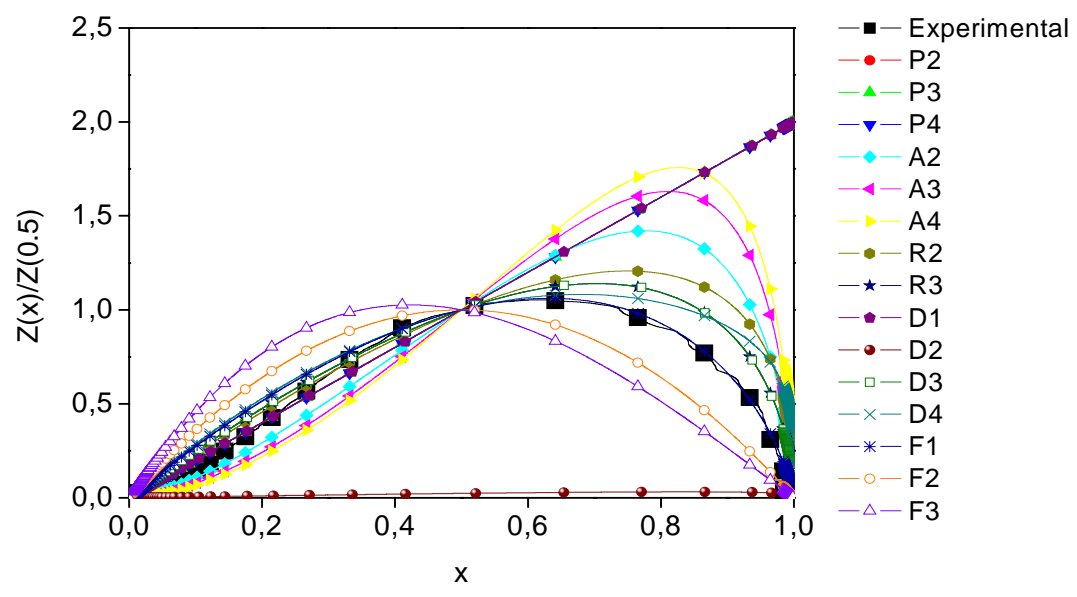

Fig. 9. Masterplots of different kinetic models and experimental data at $10 \mathrm{~K} / \mathrm{min}$ calculated by Eq. (13) for HDPE degradation

plots A4 and D4. The degradation of the mixture corresponds to models D4 and F1.

In order to determine the most probable model, Coats-Redfern method was used. According to Eq. (12), activation energy at $10 \mathrm{~K} / \mathrm{min}$ for every $g(x)$ function listed in Table 1 can be calculated from fitting $\ln \left(g(x) / T^{2}\right)$ versus $1 / T$ plots. The corresponding activation energies and correlations are tabulated in Table 7 for HDPE, oil shale and their mixture, respectively. To

Table 7. Activation energies of HDPE, oil shale and mixture obtained by CoatsRedfern method

\begin{tabular}{|c|c|c|c|c|c|c|}
\hline \multirow{2}{*}{ Model } & \multicolumn{2}{|c|}{ HDPE } & \multicolumn{2}{c|}{ Oil Shale } & \multicolumn{2}{c|}{ Mixture } \\
\cline { 2 - 7 } & $\begin{array}{c}\text { Activation } \\
\text { energy } \\
(\mathrm{kJ} / \mathrm{mol})\end{array}$ & $\begin{array}{c}\text { Correlation } \\
\text { coefficient, }\end{array}$ & $\begin{array}{c}\text { Activation } \\
\text { energy } \\
(\mathrm{kJ} / \mathrm{mol})\end{array}$ & $\begin{array}{c}\text { Correlation } \\
\text { coefficient,r }\end{array}$ & $\begin{array}{c}\text { Activation } \\
\text { energy } \\
(\mathrm{kJ} / \mathrm{mol})\end{array}$ & $\begin{array}{c}\text { Correlation } \\
\text { coefficient,r }\end{array}$ \\
\hline P2 & 94 & 0.9882 & 7 & 0.9863 & 82 & 0.9923 \\
P3 & 61 & 0.9855 & 12 & 0.9884 & 55 & 0.9937 \\
P4 & 42 & 0.9844 & 10 & 0.9874 & 39 & 0.9943 \\
A2 & 98 & 0.9971 & 112 & 0.9887 & 98 & 0.9845 \\
A3 & 97 & 0.9970 & 62 & 0.9937 & 67 & 0.9896 \\
A4 & 72 & 0.9967 & 180 & 0.9886 & 52 & 0.9909 \\
R2 & $\mathbf{2 4 8}$ & $\mathbf{0 . 9 9 7 8}$ & 148 & 0.9887 & 160 & 0.9807 \\
R3 & 270 & 0.9981 & 163 & 0.9911 & 172 & 0.9824 \\
D1 & 406 & 0.9904 & 119 & 0.9898 & 310 & 0.9930 \\
D2 & 450 & 0.9952 & 186 & 0.9787 & 280 & 0.9896 \\
D3 & 520 & 0.9912 & 138 & 0.9612 & 262 & 0.9913 \\
D4 & 480 & 0.9954 & $\mathbf{8 0}$ & $\mathbf{0 . 9 9 8 7}$ & $\mathbf{2 1 2}$ & $\mathbf{0 . 9 9 8 9}$ \\
F1 & 317 & 0.9968 & 215 & 0.9921 & 310 & 0.9888 \\
F2 & 497 & 0.9765 & 197 & 0.9913 & 280 & 0.9922 \\
F3 & 500 & 0.9535 & 206 & 0.9903 & 295 & 0.9881 \\
\hline
\end{tabular}


elucidate the mechanism of HDPE degradation, the values of activation energies obtained by the methods above have been compared. According to the data in Table 7 it could be found that the $E$ value of HDPE degratation corresponding to mechanism R2 is in good agreement with the value obtained by Friedman method $(247 \mathrm{~kJ} / \mathrm{mol})$. Otherwise, the mechanism of thermal degradation of oil shale kerogen follows the mechanism D4. The mixture degrades following the kinetic model of D4.

\section{Conclusions}

The pyrolytic behaviour of oil shale/HDPE mixture has been investigated using a TGA apparatus. The conclusions drawn from the present work are as follows:

- Three stage are observed during co-pyrolysis of oil shale with HDPE. The first one is attributed to the release of adsorbed water from the sample. The second one corresponds to the overlapping decomposition of oil shale kerogen and HDPE. The third stage is attributed to decomposition of the mineral matter of oil shale in the mixture (carbonates and silicates).

- Co-pyrolysis of oil shale/HDPE apparently occurs without interaction reactions between oil shale fractions and HDPE components in the solid phase. However, possible gas-solid interactions or reactions in the gaseous phase and minor modifications during secondary reactions might occur.

- Pyrolysis of HDPE can be described by "Contracting cylinder" model (R2). The most probable model for the pyrolysis process of oil shale kerogen agrees with diffusion model (D4), while the mixture degrades following the kinetic model D4.

\section{REFERENCES}

1. Yusaku Sakata, Y., Uddin, M. A, Muto, A. Degradation of polyethylene and polypropylene into fuel oil by using solid acid and non-acid catalysts // J. Anal. Appl. Pyrol. 1999. Vol. 51, No. 1-2. P. 135-155.

2. Kaminsky, $W$., Predel, M., Sadiki, A. Feedstock recycling of polymers by pyrolysis in a fluidised bed // Polym. Degrad. Stab. 2004. Vol. 85, No. 3. P. 1045-1050.

3. Williams, E. A, Williams, P. T. Analysis of products derived from the fast pyrolysis of plastic waste // J. Anal. Appl. Pyrol. 1997. Vol. 40-41. P. 347-363.

4. Tillman, D. A., Rossi, A. J., Vick, K. M. Incineration of municipal and hazardous solid wastes. New York: Academic Press, 1989.

5. Liu, Z., Zondlo, J. W., Dadyburjor, D. B. Tire liquefaction and its effect on coal liquefaction // Energy and Fuels. 1994. Vol. 8, No. 3. P. 607-612. 
6. Sakurovs, $R$. Interactions between coking coals and plastics during co-pyrolysis // Fuel. 2003. Vol. 82, No.15-17. P. 1911-1916.

7. Horvat, N., Flora, T. T. Ng. Tertiary polymer recycling: study of polyethylene thermolysis as a first step to synthetic diesel fuel // Fuel. 1999. Vol. 78, No. 4. P. 459-470.

8. Uddin, A., Koizumi, K., Murata, K., Sakata, Y. Thermal and catalytic degradation of structurally different types of polyethylene into fuel oil // Polym. Degrad. Stab. 1999. Vol. 56, No. 1. P. 37-44.

9. Uzumkesici, E. S., Casal-Banciella, M. D., McRae, C., Snape, C. E., Taylor, D. Co-processing of single plastic waste streams in low temperature carbonization // Fuel. 1999. Vol. 78, No.14. P. 1697-1702.

10. Mastral, A. M., Callen, M. S., Garcia, T., Navarro, M. V. Improvement of liquids from coal-tire co-thermolysis. Characterization of the obtained oils // Fuel Process. Technol. 2000. Vol. 64, No.1-3. P. 135-140.

11. Ballice, $L$. Classification of volatile products evolved from the temperatureprogrammed co-pyrolysis of Turkish oil shales with atactic polypropylene (APP) // Energy and Fuels. 2001. Vol. 15, No. 3. 659-665.

12. Ballice, L., Yüksel, M., Sağlam, M., Reimert, R., Schulz, H. Classification of volatile products evolved during temperature-programmed co-pyrolysis of Turkish oil shales with low density polyethylene // Fuel. 1998. Vol. 77, No. 13. P. 1431-1441.

13. Tiikma, L., Luik, H., Pryadka, N. Co-pyrolysis of Estonian shales with lowdensity polyethylene // Oil Shale. 2004. Vol. 21, No. 4. P. 75-85.

14. Gersten, J., Fainberg, V., Garbar, A., Hetsroni, A., Shindler, Y. Utilization of waste polymers through one-stage low-temperature pyrolysis with oil shale // Fuel. 1999. Vol. 78, No. 8. P. 987-990.

15. Gersten, J., Fainberg, V., Hetsroni, A., Shindler, Y. Kinetic study of the thermal decomposition of polypropylene, oil shale, and their mixture // Fuel. 2000. Vol. 79, No. 13. P. 1679-1686.

16. El Harfi, K., Mokhlisse, A., Ben Chanâa, M. Effect of water vapor on the pyrolysis of the Moroccan (Tarfaya) oil shale // J. Anal. Appl. Pyrol. 1999. Vol. 48, No. 2. P. 65-76.

17. El Harfi, K., Bennouna, C., Mokhlisse, A., Ben Chanâa, M., Lemée, L., Joffre, J., Ambles, A. Supercritical fluid extraction of Moroccan (Timahdit) oil shale with water // J. Anal. Appl. Pyrol. 1999. Vol. 50, No. 2. P. 163-174.

18. El harfi, K., Mokhlisse, A., Ben Chanâa, M., Outzourhit, A. Pyrolysis of the Moroccan (Tarfaya) oil shales under microwave irradiation // Fuel. 2000. Vol. 79, No. 7. P. 733-742.

19. El Harfi, K., Mokhlisse, A., Ben Chanâa, M. Yields and composition of oil obtained by isothermal pyrolysis of the Moroccan (Tarfaya) oil shales with steam or nitrogen as carrier gas // J. Anal. Appl. Pyrol. 2000. Vol. 56, No. 2. P. 207-218.

20. Bekri, O., Ziyad, M. Synthesis of oil Shale R\&D Activities in Morocco, Proceedings of the 1991 Eastern Oil Shale Symposium, Lexington, Kentucky, 1991.

21. Nazzal, J. M. Gas evolution from the pyrolysis of Jordan oil shale in a fixed-bed reactor // J. Therm. Anal. Cal. 2001. Vol. 65, No. 3. P. 847-857.

22. Kissinger, H. E. Reaction kinetics in differential thermal analysis // Anal. Chem. 1957. Vol. 29, No. 11. P. 1702-1706. 
23. Akahira, T., Sunose, T. Title ?? // Res. Report CHIBA Inst. Technol. 1971. Vol. 16, No. ?. P. 22-31.

24. Coats, A. W., Redfern, J. P. Kinetic parameters from thermogravimetric data // Nature. 1964. Vol. 201. P. 68-69.

25. Friedman, $H$., Kinetics of thermal degradation of char-forming plastics from thermogravimetry. Application to a phenolic plastic // J. Polym. Sci., Part C. 1964. Vol. 6, No. ?. P. 183-195.

26. Flynn, J., Wall, L. A. quick, direct method for the determination of activation energy from thermogravimetric data // Polym. Lett. 1966. Vol. 4, No. ?. P. 323 328.

27. Ozawa, T. A new method of analyzing thermogravimetric data // Bull. Chem. Soc. Jpn. 1965. Vol. 38, No. 11. P. 1881-1886.

28. Doyle, C. Kinetic analysis of thermogravimetric data // J. Appl. Polym. Sci. 1961. Vol. 5, No. 15. P. 285-292.

29. Criado, J. M. Kinetic analysis of DTG data from master curves // Termochim. Acta.1978. Vol. 24, No. 1. P. 186-189.

30. Tissot, B. P., Welte, D. H. Petroleum Formation and Occurrence. Springer, Berlin, 1978. P. 142, 538 pp.

31. Durand, B., Monin, J. C. Elemental analysis of kerogen. In: Durand, B. (Ed.), Kerogen. Technip, Paris, 1980. P. 301.

32. Thakur, D. S., Nuttall, H. E. Kinetics of pyrolysis of Moroccan oil-shale by thermogravimetry // Ind. Eng. Chem. Res. 1987. Vol. 26, No. 7. P. 1351-1356.

33. Jaber, J. O., Probert, S. D. Non-isothermal thermogravimetry and decomposition kinetics of two Jordanian oil shales under different processing conditions // Fuel Process. Technol. 2000. Vol. 63, No. 1. P. 57-70

34. Rajeshwar, $K$. The kinetics of the thermal decomposition of green river oilshale kerogen by non-isothermal thermogravimetry // Thermochim. Acta 1981. Vol. 45, No. 3. P. 253-263.

35. Agudo, R., Olazar, M., Gaisan, B., Prieto, R., Bilbao, J. Kinetic study of polyolefin pyrolysis in a conical spouted bed reactor// Ind. Eng. Chem. Res. 2002. Vol. 41, No. 18. P. 4559-4566.

36. Sorum, L., Gronli, M. G., Hustad, J. E. Pyrolysis characteristics and kinetics of municipal solid wastes // Fuel. 2001. Vol. 80, No. 9. P. 1217-1227.

37. Wu, C. H., Chang, C. Y., Hor, J. L., Shih, S. M., Chen, L. W., Chang, F. W. On the thermal treatment of plastic mixtures of MSW: Pyrolysis kinetics // Waste Mgmt. 1993. Vol. 13, No. 3. P. 221-235.

38. Torrente, M. C., Galan, M. A. Kinetics of the thermal decomposition of oil shale from Puertollano (Spain) // Fuel. 2001. Vol. 80, No 3. P 327-334.

39. Sonibare, O. O., Ehinola, O. A., Egashira, R. Thermal and geochemical characterization of Lokpanta oil shales, Nigeria // Energy Convers. Mgmt. 2005. Vol. 46, No. 15-16. P. 2335-2344.

40. Dogan, O. M, Uysal, B. Z. Non-isothermal pyrolysis kinetics of three Turkish oil shales // Fuel. 1996. Vol. 75, No. 12. P. 1424-1428.

Presented by M. V. Kök

Received February 23, 2006 